\title{
Malignant Biliary Obstruction: Clinical Outcome of Endoscopic Intervention - An Experience of Tertiary Centers
}

\author{
MM KABIR ${ }^{\mathrm{a}}$, MA MASUD ${ }^{\mathrm{b}}$, MM RAHMAN ${ }^{\mathrm{c}}$ MN MOQUE ${ }^{\mathrm{d}}$, SM HOSSAIN $^{\mathrm{e}}$, TM BHUIYAN ${ }^{\mathrm{f}}$, \\ MM ALAMg, MS ARFIN ${ }^{\mathrm{h}}$, MA RAHMAN ${ }^{\mathrm{i}}$, AQM MOHSEN ${ }^{\mathrm{j}}$, AKA KHAN ${ }^{\mathrm{k}}$
}

\begin{abstract}
Summary:
Most patients with malignant obstructive jaundice present at a stage when they are beyond the scope of curative surgery. Endoscopic stenting is the approach of choice worldwide to improve quality of life and survival of such patients. The aim of this study was to find out overall clinical outcome of endoscopic intervention in malignant obstructive jaundice. This prospective study done in two tertiary gastroenterology centers in Dhaka included consecutively admitted 79 adult patients with malignant biliary obstruction for endoscopic stenting, followed by a follow-up period of six months. Outcome evaluation included success rate of stenting and drainage, complications, and mortality rate at one-month, and survival up to six-months. ERCP revealed carcinoma of pancreas, periampullary carcinoma, cholangiocarcinoma,
\end{abstract}

a. Dr. Md. Mohsin Kabir, MBBS, MD (Gastroenterology), Medical Officer, Department of Gastrointestinal, Hepatobiliary \& Pancreatic Disorders (GHPD), Bangladesh Institute of Research \& Rehabilitation in Diabetes, Endocrine \& Metabolic Disorders (BIRDEM) Hospital, Dhaka, Bangladesh.

b. Dr. Md. Abdul Masud, MBBS, MD (Gastroenterology), FCPS (Internal Medicine), Associate Professor of Gastroenterology, Dhaka Medical College, Dhaka, Bangladesh.

c. Dr. Md. Mohibur Rahman, MBBS, FCPS (Internal Medicine), MD (Gastroenterology). Assistant Professor of Gastroenterology, Sahabuddin Medical College, Gulshan, Dhaka.

d. Dr. Md. Nazmul Hoque, MBBS, MD (Gastroenterology), Medical Officer, Department of Gastrointestinal, Hepatobiliary \& Pancreatic Disorders (GHPD), BIRDEM Hospital, Dhaka, Bangladesh.

e. Dr. Shafiuddin M Hossain, MBBS, Managing Director, Gastroliver Hospital \& Research Institute, Dhaka, Bangladesh.

f. Dr. Tareq Mahmud Bhuiyan, MBBS, FCPS (Internal Medicine), Assistant Professor, Department of Gastro-intestinal, Hepatobiliary \& Pancreatic Disorders (GHPD), BIRDEM Hospital, Bangladesh.

g. Dr. Md. Mahbub Alam, MBBS, PhD, MRCR, Assistant Professor, Department of Gastrointestinal, Hepatobiliary \& Pancreatic Disorders (GHPD), BIRDEM Hospital, Bangladesh.

h. Dr. Md. Shamsul Arfin, MBBS, FCPS (Internal Medicine), Associate Professor, Department of Gastrointestinal, Hepatobiliary \& Pancreatic Disorders (GHPD), BIRDEM Hospital, Bangladesh

i. Prof. Md. Anisur Rahman, MBBS, FCPS (Internal Medicine), Professor, Department of Gastrointestinal, Hepatobiliary \& Pancreatic Disorders (GHPD), BIRDEM Hospital, Bangladesh.

j. Prof. AQM Mohsen, MBBS, FCPS (Internal Medicine), Professor, Department of Gastrointestinal, Hepatobiliary \& Pancreatic Disorders (GHPD), BIRDEM Hospital, Bangladesh.

k. Dr. Abul Kalam Azad Khan, MBBS, FCPS (Internal Medicine), D Phil (Oxon), Honorary Senior Consultant, Department of Gastrointestinal, Hepatobiliary \& Pancreatic Disorders (GHPD), BIRDEM Hospital, Bangladesh.

Address of correspondence: Dr. M A Masud, Associate Professor of Gastroenterology, Dhaka Medical College, Dhaka-1000, Tel: 8626815 /

2775, Fax: None, e-mail: masud@asiatelnet.com carcinoma of gallbladder, and metastasis in the biliary trees in 22 (27.8\%), 22 (27.8\%), 20 (25.3\%), 11 (13.9\%), and 04 (5.1\%) cases respectively. Successful stenting and drainage could be achieved in $62(78.5 \%)$ and 58 (73.4\%) cases. Stent blockage (23.9\%) and cholangitis (19.4\%) were the main complications. Total death at one-month was nine of 55 (16.4\%), and 21 (38.2\%) patients survived up to six-months, with no difference in one-month mortality rate among the malignancies $(P>0.05)$. Stenting prolonged six-month (88.2\%) and mean survival (121.2 \pm 67.7 days) only in patients with periampullary carcinoma $(P<0.001)$.

Endoscopic stenting can safely be done in malignant biliary obstruction to offer palliation with an outcome, which is not unsatisfactory.

(J Bangladesh Coll Phys Surg 2006; 24: 61-68)

\section{Introduction:}

Surgery is the standard treatment of malignant biliary obstruction, the second most common cause of obstructive jaundice. Unfortunately in only $20 \%$ patients these malignant lesions are resectable, except ampullary tumours ${ }^{1-7}$. With inoperable biliary tumours the prognosis is poor in terms of survival and quality of life ${ }^{8,9}$. Endoscopic biliary drainage is an established procedure of palliation in such situation to relieve jaundice, and to help maintain a good quality survival $^{10-19}$. Lower procedure-related complications and the relative non-invasive nature of endoscopic treatment have relegated surgical management to a subsidiary role ${ }^{20-28}$.

Endoscopic retrograde cholangiopancreatography (ERCP) is done in several centers in Bangladesh for more than one and half decade. With malignant obstructive jaundice patients are admitted at the 'Bangladesh Institute of Research \& Rehabilitation in Diabetes, Endocrine \& Metabolic Disorders' (BIRDEM) Hospital, and other institutions, and during ERCP many of them receive endoscopic stenting, if found unfit for surgery. Hasan et $\mathrm{al}^{29}$ reported their experience of diagnostic ERCP in a study done in Dhaka. However, till now there is no published report on the outcome of endoscopic 
intervention in patients with malignant obstructive jaundice. A study was therefore conducted on 79 patients, and we report the experiences on success rate of endoscopic stenting, successful drainage achieved, about early and late complications, and the impact of endoprosthesis implantation on quality of life and survival.

The purpose of this study was to obtain the results of endoscopic palliation in patients with malignant biliary obstruction.

\section{Materials and method:}

Irrespective of sex, consecutively admitted 79 adult patients with features of malignant obstructive jaundice were included in this prospective study during April to December 2000. This study was done in the Bangladesh Institute of Research \& Rehabilitation in Diabetes, Endocrine \& Metabolic Disorders (BIRDEM) Hospital, and in Gastro liver Hospital \& Research Institute, Dhaka, the tertiary gastroenterology centres of this country. The purpose of this study was explained to every patient, and they were included after they gave their verbal consent. Common bile duct diameter of more than $8 \mathrm{~mm}$ in ultrasonogram was considered as an evidence of biliary obstruction ${ }^{30}$. Besides ultrasonography and before ERCP liver function and relevant biochemical tests, CT scan of abdomen was done in all the patients. Duodenoscope (Fujinon, 400 series) with a working channel of 4.2 and $3.8 \mathrm{~mm}$. were used for ERCP. Biopsy was obtained only in case of suspected periampullary carcinoma, or carcinoma of head of the pancreas infiltrating the duodenum. In all other cases diagnosis was done correlating cholangiographic findings with clinical and laboratory features. Neither collection of juice from common bile duct (CBD), nor any brush cytology was included for histological diagnosis. Irrespective of type or site of lesions endoprosthesis implantation was the objective. Plastic stents, 10Fr., or in some cases $7 \mathrm{Fr}$. (Amsterdam type), with flaps on either end were used for this purpose. In case of hilar obstruction, the aim was to implant only unilateral stenting.
Successful endoscopic stenting and drainage were defined respectively as passage of endoprosthesis across the stricture with restoration of bile flow, and at least a $30 \%$ reduction of serum bilirubin within 10 days of intervention, with recovery from cholangitis, if any. Early complication and onemonth mortality were defined as those events occurring within 30 days of the first attempt of endoscopic intervention.

After discharge from the hospital, follow up of all the patients were done at the interval of 15 to 30 days, for six months. Follow up included history taking, physical examination, and laboratory investigations, if needed. Monitoring was done over telephone in case any patient was unable to attend the outpatient department. No one was lost to follow up. After recurrence of biliary obstruction a review ERCP was done, followed by restenting, if needed.

Outcome evaluation included success rate of stenting and drainage, morbidity of the procedure, patient's mortality at one-month, and survival up to six month.

\section{Exclusion criteria:}

Patients with malignant biliary obstruction, but having marked narrowing of the duodenal channel or any other morbid diseases were not included in this study.

Statistical Analysis: Statistical analysis was done using SPSS software. The significance level in comparison between variables was set at 0.05 .

\section{Results:}

\section{Entry characteristics:}

Of the 79 patients, $50(63.3 \%)$ were male and 29 $(36.7 \%)$ female with an age range of 23-85 years (mean $56.3 \pm 12.0 y r s$ ). Majority patients were in the age group of 51-70 years (59.5\%) [Table-I]. Major clinical features were pruritus $(74.7 \%)$, abdominal pain $(65.8 \%)$, weight loss $(49.4 \%)$, weakness $(48.1 \%)$, anorexia $(35.4 \%)$, fever $(25.3 \%)$, and nausea $(24.1 \%)$. Mean duration of jaundice was $67 \pm 26.7$ days, with their serum bilirubin and alkaline phosphatase level of $12.5 \pm 5.9 \mathrm{mg} / \mathrm{dl}$ and $1132 \pm 802$ IU/L respectively. 


\section{Table-I}

\section{Patients characteristics- at entry \& after ERCP.}

\begin{tabular}{|c|c|c|c|c|c|c|c|c|c|c|}
\hline \multirow[b]{2}{*}{ Gender } & \multicolumn{10}{|c|}{$\begin{array}{c}\text { At entry } \\
\text { Age Range }\end{array}$} \\
\hline & \multicolumn{2}{|c|}{$23-30$} & \multicolumn{2}{|c|}{$31-50$} & \multicolumn{2}{|c|}{$51-70$} & \multicolumn{2}{|c|}{$\geq 71$} & \multicolumn{2}{|c|}{ Total } \\
\hline Male & \multicolumn{2}{|c|}{$01(1.3)$} & \multicolumn{2}{|c|}{$15(19)$} & \multicolumn{2}{|c|}{$29(36.7)$} & \multicolumn{2}{|c|}{$05(6.3)$} & \multicolumn{2}{|c|}{50} \\
\hline Female & \multicolumn{2}{|c|}{$02(2.5)$} & \multicolumn{2}{|c|}{$08(10.1)$} & \multicolumn{2}{|c|}{$18(22.8)$} & \multicolumn{2}{|c|}{$01(1.3)$} & \multicolumn{2}{|c|}{29} \\
\hline \multicolumn{11}{|c|}{ Findings after ERCP } \\
\hline \multirow[t]{2}{*}{ Characters } & \multicolumn{2}{|c|}{$\begin{array}{l}\text { Periam- } \\
\text { carcinoma }\end{array}$} & \multicolumn{2}{|c|}{$\begin{array}{l}\text { Carcinoma- } \\
\text { pancreas }\end{array}$} & \multicolumn{2}{|c|}{$\begin{array}{l}\text { Cholangio } \\
\text { Carcinoma- }\end{array}$} & \multicolumn{2}{|c|}{$\begin{array}{l}\text { Carcinoma- } \\
\text { gallbladder }\end{array}$} & \multicolumn{2}{|c|}{ Metastasis } \\
\hline & $\mathrm{M}$ & $\mathrm{F}$ & M & $\mathrm{F}$ & M & $\mathrm{F}$ & M & $\mathrm{F}$ & $\mathrm{M}$ & $\mathrm{F}$ \\
\hline$\leq 50(\mathrm{yrs})$ & 09 & 02 & 02 & 02 & 05 & 02 & & 02 & & 01 \\
\hline$\geq 51(\mathrm{yrs})(54) \dagger$ & 07 & 04 & 13 & 05 & 08 & 05 & 05 & 04 & 01 & 02 \\
\hline $\begin{array}{l}\text { Mean age } \\
\text { (years) }\end{array}$ & \multicolumn{2}{|c|}{$51.64 \pm 11.5$} & \multicolumn{2}{|c|}{$59.6 \pm 12.1$} & \multicolumn{2}{|c|}{$57.1 \pm 10.9$} & \multicolumn{2}{|c|}{$59.9 \pm 10.8$} & \multicolumn{2}{|c|}{$49.5 \pm 17.8$} \\
\hline Age range (years) & \multicolumn{2}{|c|}{$29-75$} & \multicolumn{2}{|c|}{$26-85$} & \multicolumn{2}{|c|}{$45-78$} & \multicolumn{2}{|c|}{$40-78$} & \multicolumn{2}{|c|}{$23-61$} \\
\hline
\end{tabular}

$\dagger$ Male sex $\mathrm{P} \leq 0.05$, [between two different age range $\leq 50$ and $\geq 51$ ]

Findings after ERCP:

ERCP was done in all the 79 patients. Findings were suggestive of carcinoma of pancreas, periampullary carcinoma, cholangiocarcinoma, carcinoma of gallbladder and biliary tree in $22(27.8 \%), 22$ (27.8\%), 20 (25.3\%), 11 (13.9\%) and 04 (5.1\%) cases respectively. Higher distribution of these malignancies, except periampullary carcinoma, was seen after the age of 50 years, but, significantly, only in case of male $(43 \%)(\mathrm{P}<0.05)$ (Table-I). Of the 20 cases of cholangiocarcinoma, twelve were seen in the perihilar region (type I-one, type II-three, type IIIbtwo, and type IV-six), and rest eight were in the extrahepatic bile duct. Biopsy obtained in 27 patients from obvious lesions in ampullary region revealed periampullary carcinoma in 22 cases, carcinoma of pancreas in four, and cholangiocarcinoma in one.

\section{Endoscopic intervention and outcome:}

In three patients with periampullary carcinoma papillotomy was done with no stenting, which restored adequate biliary drainage. Endoscopic palliation was not attempted in 12 patients due to unsuitable cholangiographic picture, and in five patients attempt of stenting was unsuccessful. However, it was done successfully in rest 59 patients that included 18 cases with periampullary carcinoma, 18 with carcinoma of pancreas, 12 with cholangiocarcinoma, 10 with carcinoma of gall bladder and one with biliary metastasis [Table-II]. Within two days of stenting two patients expired, and there was no improvement in another two. With an intention to treat basis successful stenting, and drainage could be done in 62(78.5\%), and 58(73.4\%) cases respectively.

After unsuccessful attempt of stenting in five patients three of them were treated by PTBD (percutaneous transhepatic biliary drainage). Two of the 12 patients, not included for endoscopic intervention also received PTBD. Rest 12 patients left abandoned without any intervention died within one month. Within the same period there was death of one patient after PTBD. Following successful stenting Whipple's operation was done in four cases with periampullary carcinoma, and two with carcinoma of pancreas. However, two days after surgery, one patient died of 


\section{Table-II}

Post-ERCP endoscopic management, showing distribution in relation to malignancy \& age-range

\begin{tabular}{|c|c|c|c|c|c|c|c|}
\hline \multirow[t]{2}{*}{ Malignancies } & \multicolumn{2}{|c|}{$\begin{array}{l}\text { Papillotomy and } \\
\text { stenting }\end{array}$} & \multicolumn{2}{|c|}{$\begin{array}{c}\text { ERCP } \\
\text { abandoned }\end{array}$} & \multicolumn{2}{|c|}{$\begin{array}{l}\text { ERCP } \\
\text { Failed }\end{array}$} & \multirow[t]{2}{*}{$\begin{array}{c}\mathrm{P} * \\
\text { value }\end{array}$} \\
\hline & $\overline{\leq 50}$ & $\geq 51$ & $\leq 50$ & $\geq 51$ & $\overline{\leq 50}$ & $\geq 51$ & \\
\hline Periampullar-ca $\ddagger$ & 11 & 10 & & 01 & & & \\
\hline Ca-pancreas & 03 & 15 & 01 & 02 & & 01 & $\geq 0.05$ \\
\hline Cholangiocarcinoma & 05 & 07 & 01 & 04 & 01 & 02 & \\
\hline Ca-gallbladder & 02 & 08 & 01 & 00 & & & \\
\hline Metastasis & 01 & 0 & 0 & 02 & & 01 & \\
\hline Total & $\begin{array}{c}22 \\
(27.8)\end{array}$ & $\begin{array}{c}40 \\
(50.6)\end{array}$ & $\begin{array}{c}3 \\
(3.8)\end{array}$ & $\begin{array}{c}09 \\
(11.4)\end{array}$ & $\begin{array}{c}01 \\
(1.3)\end{array}$ & $\begin{array}{c}04 \\
(5.1)\end{array}$ & \\
\hline
\end{tabular}

$\ddagger$ Papillotomy was done in three patients without stenting.

* Each procedure of two-age range $[\leq 50, \& \geq 51]$

adult respiratory distress syndrome (ARDS). But rest six survived for more than six months. After stenting, palliative surgery was done in a patient with cholangiocarcinoma, who had marked stricture in the common hepatic duct. (Table-IV). He also survived for six months.

Early complications and death after endoscopic intervention:

Different complications were seen in $11(16.4 \%)$ patients within 30 days of an attempt of intervention in 67 cases. During procedure significant bleeding started from papillotomy site in two $(3.0 \%)$ patients, and perforation occurred in one $(1.5 \%)$. Two days later, cholangitis, acute pancreatitis, and peritonitis were noticed in 03 (4.5\%), 02 (3.0\%) and 03 (4.5\%) patients respectively; and all these complications were seen mostly with distal malignancies (Table-III). With conservative management they recovered well.

One month after endoscopic drainage total death was nine of $55(16.4 \%)$, and there was no significant difference in patients' mortality rate with different malignancies $(\mathrm{P}>0.05)$ (Table-IV).

Late complications after endotherapy:

Forty-six patients were alive after one month of intervention. At variable intervals (median four months) 14 (30.4\%) patients presented with jaundice and of them $10(21.7 \%)$ with cholangitis (Table-III). Review ERCP revealed stent blockage in 11 (23.9\%) cases. Restenting was done once in eight patients, and on two occasions in other three relieved biliary obstruction. Jaundice in rest three patients was due to blockage of bile flow at the CBD outflow tract by extension of tumour mass of periampullary carcinoma. This time they received their first stenting. Two (4.3\%) patients suffering from cholangiocarcinoma presented with liver abscess as a late complication, but recovered with conservative management.

\section{Survival at six month (after stenting)}

Finally $21(38.2 \%)$ patients were alive after a sixmonth follow up. With carcinoma of gallbladder (10), and biliary metastasis (01) none survived up to six months (Table-IV). Mean survival with the former was $88.7 \pm 47.1$ days; and with the later, the survival was 35 days only. With cholangiocarcinoma and carcinoma of pancreas, 04 (36.4\%) and 02 (12.5\%) patients were alive after six months, and mean survival with these malignancies were 114.5 \pm 77.2 and $97.6 \pm 64.5$ days respectively. However, with periampullary carcinoma, $15(88.2 \%)$ patients were alive after six months, a difference with others, which was statistically significant $(\mathrm{P}<0.001)$ (Table-IV). Age, sex, or site of lesion did not influence the outcome of endoprosthesis. 


\section{Table-III}

Early and late complications after attempt of endoscopic intervention

Type of

Complications

Bleeding

Perforation

Cholangitis

Pancreatitis

Peritonitis

Liver abscess

Stent blockage

Total

06

02

02
No. of patients / period after intervention

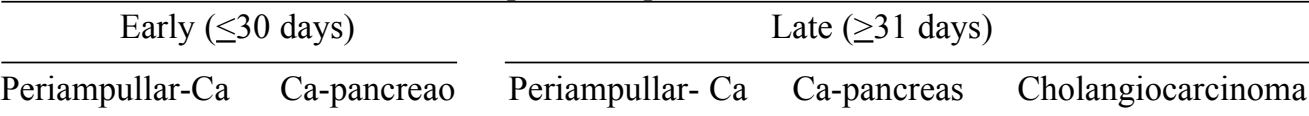

01

01

03

\begin{tabular}{cccc} 
& & & 02 \\
06 & 05 & 05 & 01 \\
05 & 11 & 08 & 04 \\
\hline
\end{tabular}

\section{Table-IV}

Survival of patients in days after different procedures / management

\begin{tabular}{|c|c|c|c|c|c|c|c|c|}
\hline \multirow[t]{2}{*}{$\begin{array}{l}\text { Diseases / } \\
\text { Characters }\end{array}$} & \multicolumn{2}{|c|}{$\begin{array}{l}\text { Papillotomy/ } \\
\text { stenting } \\
n=55\end{array}$} & \multirow{2}{*}{$\begin{array}{c}\text { Abandoned } \\
\text { Failed } 9 \\
\text { n=12 } \\
\leq 30\end{array}$} & \multicolumn{2}{|c|}{$\begin{array}{c}\text { Surgery } \\
\mathrm{n}=07\end{array}$} & \multicolumn{2}{|c|}{$\begin{array}{c}\operatorname{PTBD} \varphi \\
\mathrm{n}=5\end{array}$} & \multirow[t]{2}{*}{$\begin{array}{c}\mathrm{P} * \\
\text { value } \\
<0.001\end{array}$} \\
\hline & $\leq 30 \S$ & $\geq 180$ & & $\leq 30$ & $\geq 180$ & $\leq 30$ & $\geq 180$ & \\
\hline Periampullar-ca & $01(5.9 \%)$ & $15(88.2 \%)$ & 01 & 01 & 03 & & & \\
\hline Ca-pancreas & $04(25 \%)$ & $02(12.5 \%)$ & 03 & & 02 & & & \\
\hline Cholangio-carcinoma & $03(27.3 \%)$ & $04(36.4 \%)$ & 06 & & 01 & & 01 & \\
\hline $\begin{array}{l}\text { Carcinoma } \\
\text { gallbladder }\end{array}$ & $01(10 \%)$ & & & & & & & $<0.001$ \\
\hline Metastasis & & & 02 & & & 01 & & \\
\hline Total & $09(16.4 \%)$ & $21(38.2 \%)$ & $12(15.2 \%)$ & 01 & 06 & 01 & & \\
\hline $\begin{array}{l}\text { Mean survival } \phi \\
\text { (days) }\end{array}$ & 121 & \pm 67.7 & $12.1 \pm 8.3$ & 154 & $=67.3$ & & 63.1 & \\
\hline
\end{tabular}

$\S P \geq 0.05$,

* Between malignancies (long-term survival)

$\varphi$ PTBD (percutaneous transhepatic biliary drainage) done after attempt of stenting abandoned / attempt failed

I No sort of intervention was done

$\phi$ Mean of all the patients with individual management

Percentage done in each category of patients 


\section{Discussion:}

This is the first study in this country to find out a data on the outcome of endobiliary prosthesis implantation which was conducted on 79 patients with jaundice of $67 \pm 26.7$ days duration. Carcinoma of the pancreas, gallbladder, or bile ducts is the cause of malignant obstruction of the biliary trees ${ }^{31,32}$. Some western studies have reported pancreatic malignancy as the most common cause $\mathrm{e}^{33,34}$. In this study carcinoma of pancreas, periampullary carcinoma and cholangiocarcinoma were found as the common biliary malignancies, which together comprised $81 \%$ of all the cases, with a prevalence rate varying from $25-28 \%$ for each of them. Kapoor and McMichael 35 reported a higher prevalence of carcinoma of gallbladder in north and central India. However, in our study carcinoma of gall bladder could be detected in $11(13.9 \%)$ cases only. This variation is not unexpected as this study was done on different race and population, and it is unusual that all the patients with obstructive biliary malignancies would come to us for palliation.

With an intention to treat basis the success rate of stenting and drainage, that was achieved in $78.5 \%$ and $73.4 \%$ cases respectively is relatively lower to others. De Palma et $\mathrm{al}^{9}$ from Italy reported this outcome in $96.7 \%$ patients; and similar higher rate of success has even been reported by some other studies $6,24-27$. One of the possible reasons was biliary obstruction of advanced duration, for which stenting had to be abandoned in 12 cases. However, the drainage that was achieved in $73.4 \%$ patients was successful as there was gradual improvement of pruritus, fever and anorexia followed by that of jaundice and general well being. Luman et al ${ }^{25}$ and few others ${ }^{15,24-25}$ reported a similar outcome on quality of life after endoscopic intervention. After stenting average hospital stay of these patients was three days on an average. Plastic stents were however in all these cases.

Apparently, no difference was found in morbidity pattern when compared it to others. ${ }^{6-9}$ Early complications were seen in $11(16.4 \%)$ cases, with cholangitis in $4.5 \%$ of them. Polydorou et al ${ }^{8}$ in his study reported the same result in $19.1 \%$ and $7 \%$ cases respectively. Overall complications have even been reported in 19-27\% patients ${ }^{27-28}$. Probably use of prophylactic antibiotic in each and every patient had a role in reducing the morbidity. One month mortality rate was $16.4 \%$, which was relatively higher in patients with cholangiocarcinoma and carcinoma of pancreas than others. None of these findings differ from other published reports 8,36 . Similarly, if it is analyzed, $11(23.9 \%)$ patients presented with jaundice due to stent blockage, and 10 $(21.7 \%)$ of them with cholangitis, a higher rate of late complications, as it appears. But some other studies have found the same morbidity in $30 \%$ and $16.3 \%$ cases respectively $9,22-25$.

Long-term survival did not reveal a favourable finding as only $21(38.2 \%)$ patients survived up to six months, including none with carcinoma of gallbladder and biliary metastasis. The outcome was even poorer with carcinoma of pancreas (12.5\%). However, the picture was totally different with periampullary carcinoma, as six-month survival was $88.2 \%$. This was probably due to relatively benign course of the disease. Polydorou et $\mathrm{al}^{8}$ in his study reported shorter survival of patients with carcinoma of pancreas and biliary metastasis in comparison to others. In this study, in addition, the outcome was also worse with carcinoma of gallbladder. Weaver et al ${ }^{18}$ in his study reported a long-term survival rate of $20.4 \%$ only. However, they did their follow up for over one year. In this study, out of survived 21 cases. If $15(88.2 \%)$ with periampullary carcinoma are taken in consideration, then only six $(10.9 \%)$ patients survived up to six month, a rate which is much lower to Weaver et al ${ }^{18}$.

Overall clinical outcome achieved in this study is not comparable to those reported in western countries $8,9,15,21-24,27-28$. Whether biliary obstruction of advanced duration, and or re-use of accessories, or use of plastic stents affected the results remains to be explored, as there was no control group of patients. There are some of the limitations of this study. Follow up period was shorter, and there was no option of brush cytology or no biopsy was there to do a histological diagnosis for all the patients. However, the main goal was to find out a data of endoscopic intervention in patients with malignant biliary obstruction, and that was obtained. In that sense, this study has served the primary purpose. 
In conclusion, it may be said that carcinoma of pancreas, periampullary carcinoma and cholangiocarcinoma are the common obstructive biliary malignancies in the patients with malignant obstructive jaundice. Endoscopic palliation reduces one-month mortality, and improves quality of life. However, long-term survival is not significantly prolonged, except in periampullary carcinoma. It may also be said that in patients with malignant jaundice endoscopic intervention can safely be done with an outcome, which is not unacceptable. This study provides a rationale to do properly designed further studies on a larger number of such patients.

\section{Acknowledgements:}

The authors are grateful to the authority of the following institutes in that they allowed to conduct this study.

1. Department of Gastrointestinal, Hepatobiliary \& Pancreatic Disorders (GHPD), Bangladesh Institute of Research \& Rehabilitation in Diabetes, Endocrine \& Metabolic Disorders (BIRDEM) Hospital, Dhaka, Bangladesh.

2. Gastro Liver Hospital \& Research Institute, 69/D, Panthopath, Dhaka, Bangladesh.

\section{References:}

1. Majno PE, Azoulay D, Bismuth H. Malignant biliary obstruction. In: Bircher J, Benhamon JP, McIntyre N, Rizzetto M, Rodes (J editors). Oxford Textbook of Clinical Hepatology, second edition, Vol-II. New York. Oxford University Press. 1999. pp- 1530-45.

2. Castells A, Kroser J, Rustgi AK. Gastrointestinal neoplasms. Beers MH, Berkow R. Editors. In: The Merck manual of geriatrics. Third edition. Whitehouse Station NJ Merck 2000; 1134-53.

3. DE Groen PC, Gores GJ, La Russo NF, Gunderson LL, Nagorney DM. Biliary tract cancers. New Engl J Med 1999; 341:1368-80.

4. Warshaw AL, Fernández-del-Castillo C. Pancreatic Carcinoma. N Engl J Med. 1992; 326:455-65.

5. Tibble JA, Cairns SR. Role of endoscopic endoprosthesis in proximal malignant biliary obstruction. J Hepatobiliary Pancreat Surg 2001; 8: 118-23.

6. Born P, Rosch T, Bruhl K, et al. Long-term outcome in patients with advanced hilar bile duct tumors undergoing palliative endoscopic or percutaneous drainage. $\mathrm{J}$ Gastroenterol 2000; 38: 483-9.
7. Bathe OF, Pacheco JT, Ossi PB, Hamilton KL, Management of hilar bile duct carcinoma. Hepatogastroenterology 2001; 48: 1289-94.

8. Polydorou AA, Cairns SR, Dowsett JF, et al. Palliation of proximal malignant biliary obstruction by endoscopic endoprosthesis insertion. Gut 1991; 32: 685-89.

9. De Palma GD, Rega M, Persico M. Endoscopic palliation of inoperable hilar biliary carcinoma with self-expanding metal stents. Minerva Chir 2004; 59: 249-53.

10. Cubiella J, Castells A, Fondevila C, et al. Prognostic factors in nonresectable pancreatic adenocarcinoma: a rationale to design therapeutic trials. Am J Gastroenterol 1999; 94:12718

11. Pinol V, Castells A, Bordas JM, et al. Percutaneous selfexpanding metal stents versus endoscopic polyethylene endoprosthesis for treating malignant biliary obstruction. Randomized clinical trial. Radiology 2002; 225: 27-34.

12. Ashton CE, McNabb WR, Wilkinson ML, Lewis RR. Endoscopic retrograde cholangiopancreatography in elderly patients. Age Ageing. 1998; 27: 683-8.

13. Siegel JH, Kasmin FE. Biliary tract diseases in the elderly: management and outcomes. Gut 1997; 41: 433-5.

14. Labenz J. Biliary diseases in the elderly: diagnosis and therapy. Z Gerontol 1993; 26: 285-92.

15. Pellicer Bautista F, Martin Guerrero JM, Fernandez Perez FJ, et al. Endoscopic stenting in the management of malignant biliary obstruction. Rev Esp Enferm Dig. 1998; 90: 73-84.

16. Rothschild JG, Kaplan MM, Millan VG, et al. Management of biliary obstruction. A comparison of percutaneous, endoscopic, and operative techniques. Arch Surg 1989; 124: 556-9.

17. Soehendra N, Grimm H. Endoscopic retrograde drainage for bile duct cancer. World J Surg 1988; 12: 85-90.

18. Weaver SA, Stacey BS, Hayward SJ, et al. Endoscopic palliation and survival in malignant biliary obstruction. Dig Dis Sci 2001; 46: 2147-53

19. Cowling MG, Adam AN. Internal stenting in malignant biliary obstruction. World J Surg 2001; 25: 355-9.

20. Soehendra N, Binmoeller KF, Grimm H. Endoscopic therapy for biliary obstruction. World J Surg 1992; 16: 1066-73.

21. Cotton PB. Critical appraisal of therapeutic endoscopy in biliary tract diseases. Annul Rev Med. 1990; 41: 211-22.

22. Blom D, Schwartz SI. Surgical treatment and outcomes in carcinoma of the extrahepatic bile ducts: the University of Rochester experience. Arch Surg 2001; 136: 209-15.

23. Schoenthaler R, Phillips TL, Castro J, et al. Carcinoma of the extrahepatic bile ducts. The University of California at San Francisco experience. Ann Surg 1994; 219: 267-74. 
24. Doglietto GB, Alfieri S, Pacelli F, et al. Extrahepatic bile duct carcinoma: a western experience with 118 consecutive patients.Hepatogastroenterology 2000; 47: 349-54.

25. Luman W, Cull A, Palmer KR. Quality of life in patient's stented for malignant biliary obstruction. Eur J Gastroenterol Hepatol 1997; 9: 481-4.

26. Freeman ML, Sielaff TD. A modern approach to malignant hilar biliary obstruction. Rev Gastroenterol Disord 2003; 3 : 187-201.

27. Muminhodzic K. Endoscopic therapy of biliary Obstruction. Med Arh 2002; 56: 23-4.

28. McLean G K, Burke D R. Role of endoprostheses in the management of malignant biliary obstruction. Radiology. 1989; 170: 961-7

29. Hasan M, Rahman MT, Khorshed Alam AKM, Azad Khan A K. Endoscopic Retrograde Cholangiopancreatography: Experience of 100 cases at IPGMR. J Bang Coll Phys and Surg. 1990; 8:8-13

30. Costamagna G, Gabrielli A, Mutignani M, et al. Endoscopic diagnosis and treatment of malignant biliary strictures: Review of 505 patients. Acta Gastroenterol Belg 1993; 56: 201-6.
31. Hu B, Zhou D, Gong B. The evaluation of endoscopic biliary drainage for 288 patients with malignant hilar obstruction. Zhonghua Wai Ke Za Zhi 1997; 35: 73-6.

32. Doctor N, Dick R, Rai R, Dafnios N, Salamat A, Whiteway $\mathrm{H}$, et al. Result of percutaneous plastic stents for malignant distal biliary obstruction following failed endoscopic stent insertion and comparison with current literature on expandable metallic stents. Eur J Gastroenterol Hepatol. 1999; 11: 775-80

33. Kozarek RA. Metallic biliary stents for malignant obstructive jaundice: a review. World J Gastroentero. 2000; 6: 643-6

34. Gandini R, Fabiano S, Pipitone V, et al. Management of biliary neoplastic obstruction with two different metallic stents implanted in one session. Cardiovasc Intervent Radiol. 2005; 28 : 48-52.

35. Kapoor VK, McMichael AJ. Gallbladder cancer: an Indian disease. Natl Med J India 2003; 16: 209-13.

36. Brountzos EN, Petropoulos E, Kelekis NL, et al. Malignant biliary obstruction: management with percutaneous metallic stent placement. Hepatogastroenterology. 1999; 46: 2764-71. 